\title{
Needs Assessment of Emergency Department Residents in Examining and Managing Patients with Ophthalmologic Complaints
}

\author{
Kaidi Wang, MD ${ }^{1,2}$ Sarah R. Williams, MD ${ }^{3,4}$ lan Chong, MD ${ }^{4,5}$ Douglas R. Fredrick, MD ${ }^{1,6}$
}

${ }^{1}$ Department of Ophthalmology, Byers Eye Institute at Stanford,

Address for correspondence Kaidi Wang, MD, Department of Stanford University School of Medicine, Palo Alto, California Ophthalmology, Moran Eye Center, 65 Mario Capecchi Drive,

2 Department of Ophthalmology, John A Moran Eye Center, University Salt Lake City, UT 84132 (e-mail: kaidiw@gmail.com).

of Utah, Salt Lake City, Utah

${ }^{3}$ Department of Emergency Medicine, Stanford University School of Medicine, Palo Alto, California

${ }^{4}$ Stanford/Kaiser Emergency Medicine Program, Stanford University School of Medicine, Palo Alto, California

${ }^{5}$ Department of Emergency Medicine, Kaiser Permanente, San Diego, California

${ }^{6}$ New York Eye and Ear Infirmary of Mt. Sinai, New York, New York

J Acad Ophthalmol 2019;11:e50-e56.

\begin{abstract}
Keywords

- emergency medicine

- educational interventions

- ophthalmology
\end{abstract}

Purpose Emergency medicine residents are trained to deal with a variety of emergency conditions; eye emergencies represent only a small portion of their clinical experience. This study was a targeted needs assessment of the comfort level of emergency medicine residents in diagnosing and managing patients who present with an ophthalmic chief complaint, with the goal of targeting future educational interventions.

Methods This was a cross sectional survey conducted at a large tertiary-care hospital between June 2016 and August 2016. Participants were 1st, 2nd, or 3rd year emergency medicine residents in an Accreditation Council for Graduate Medical Education (ACGME)-approved emergency medicine residency.

Results The total response rate was $67.4 \%$ (29/43). The majority of residents did not expect equivalent availability of ophthalmology consultation services post-graduation. They generally believed ophthalmology and examination skills to be important to their future career and became more comfortable with the slit lamp exam through residency, although the average level of comfort was only 6.9 on a 1 to 10 scale for 3rd year residents (standard deviation $[S D]=2.6$ ). A majority of residents were not confident with their diagnostic, examination, or management skills when queried about specific ophthalmic conditions or presenting symptoms. They indicated a variety of reasons why their comfort with ophthalmologic patients was limited.

Conclusion There is both need and desire for increased ophthalmic skills training for emergency medicine residents. Given time constraints in residency training, possible solutions will need to be innovative and multifaceted in order to target this goal. received

November 25, 2018 accepted after revision March 18, 2019
DOI https://doi.org/

10.1055/s-0039-1692194. ISSN 2475-4757.
Copyright $\odot 2019$ by Thieme Medical Publishers, Inc., 333 Seventh Avenue, New York, NY 10001, USA Tel: +1(212) 584-4662.
License terms

(c) (i) $\ominus$ (\$) 
Despite literature suggesting that the number of patients with eye-related ocular complaints who present to the emergency department (ED) has increased by $30 \%$ between 2001 and 2014, ${ }^{1}$ there is still a lack of comfort amongst ED practitioners in dealing with eye-related chief complaints. In a cross-sectional survey of emergency physicians in the U.K., $26.0 \%$ received "no training" in the management of eye emergencies and $68.8 \%$ had "little or no confidence" in dealing with eye complaints. In the U.S. literature, the slit lamp exam has been identified among emergency medicine (EM) residents as one examination skill for which they are significantly under-prepared. ${ }^{2}$

This is concerning as most EDs do not have eye care professionals on site to triage or examine patients, which puts the responsibility of triaging and often treating patients to ED physicians. ${ }^{1,3}$ Furthermore, the availability of ophthalmologists on-call for EDs is not uniform and many hospitals lack access to subspecialty ophthalmology services. ${ }^{1,3}$ Given this, there is a strong need and desire for ED physicians to learn ophthalmic skills. In a national survey amongst emergency physicians in Australia, more than $90 \%$ of the respondents desired further education in "ophthalmic emergencies." 4

Our objective was to conduct a needs assessment of the comfort level of EM residents in diagnosing and managing patients who present with an ophthalmic chief complaint, with the goal of targeting future educational interventions toward these needs.

\section{Methods}

This was a cross-sectional study conducted at Stanford University Hospital and Clinics between June 2016 and August 2016. Prior to study initiation, this study was determined to be IRB (Institutional Review Board)-exempt by the Stanford IRB on the basis of being a quality improvement project. The EM residents in the Stanford/Kaiser EM program cover two Level 1 trauma centers with consultation ophthalmology services continuously available (Stanford University Hospital and Santa Clara Valley Medical Center). Additionally, residents also rotate through Kaiser Permanente Northern California (Santa Clara), where ophthalmology consultation is also available. At the time of this study, the residency program was a 3-year program, and core content training related to eye emergencies was based upon the Model of the Clinical Practice of Emergency Medicine. ${ }^{5}$ This training was provided at the bedside, during case-based didactics, and through dedicated hands-on skills laboratories. The skills laboratories were performed in collaboration with the ophthalmology department and consisted of a 2-hour basic eye skills laboratory for 1 st year residents and another 2-hour advanced skills laboratory for 3rd year residents. Bedside instruction took place when patients presented with eye concerns to the ED and was provided by either EM faculty or by on-call ophthalmology consulting house-staff if indicated. Third-year residents additionally were offered the opportunity for a 1- or 2-week ophthalmology elective.
Between June 2016 and August 2016, surveys were administered online to the entire EM residency, comprising $161 \mathrm{st}$ year residents, 14 2nd year residents, and 13 3rd year residents (R1, R2, and R3, respectively). Survey questions targeted experience and comfort level with common ophthalmic conditions or symptoms that patients present with to the ED. These survey questions were based upon review of prior literature. ${ }^{3,6,7}$ Survey completion was voluntary and anonymous. Questions were administered using the Stanford Medicine Qualtrics platform, a HIPAA (Health Insurance Portability and Accountability Act) compliant online survey platform. Survey questions are shown in -Table $\mathbf{1}$. Additionally, residents were also qualitatively queried as to their opinions on ideal methods of learning ophthalmologic diagnostic and management skills.

\section{Results}

A total of $69.2 \%(9 / 13)$ of R3s, $57.1 \%(8 / 14)$ of $R 2$ s, and $75 \%$ $(12 / 16)$ of R1s participated in the survey. This resulted in a total response rate of $67.4 \%$ (29/43).

Most EM residents, when anticipating their careers postgraduation, did not expect to have equivalent availability of ophthalmology consultation services available. Only $24.1 \%$ (7/29) of residents expected equivalent levels of ophthalmology consultation services (-Fig. 1).

EM residents overall believed ophthalmology examination and management skills would be important to their future career (-Fig. 2). On average when including all residents, importance was marked as 9.0 (standard deviation $[S D]=1.3$ ) on a 1 to 10 scale, with " 1 " being least important and " 10 " being most important. R1s rated the mean importance as 8.8 (SD $=1.5)$, $\mathrm{R} 2 \mathrm{~s}$ as $8.9(\mathrm{SD}=1.0)$, and $\mathrm{R} 3 \mathrm{~s}$ as $9.2(\mathrm{SD}=1.1)$. These differences, although trending toward increased importance for each increasing year of residency, did not reach significance on one-way ANOVA testing ( $p=0.77$ ).

Residents were also asked their average comfort with the slit lamp exam on a scale of 1 to 10 (- Fig. 3). In assessing level of comfort, R1s had a mean of $4.0(\mathrm{SD}=2.5)$, R2s had a mean of $5.4(\mathrm{SD}=1.9)$, R3s had a mean of $6.9(\mathrm{SD}=2.6)$, and all residents combined had a mean of $5.3(\mathrm{SD}=2.6)$. Oneway ANOVA testing reached significance $(p=0.03)$ when comparing these three groups. Post hoc analysis using twotailed $t$-tests assuming unequal variances revealed that the R1 and R3 comparison was the driver of this significance $(p=0.02)$.

-Figures 2 and 3 present the above data in box-andwhisker plot format, with whiskers representing minimum and maximum responses, and stacked boxes representing $25 \%$ percentile, median, and $75 \%$ percentile of responses.

For questions 4 and 5 of the survey, residents were asked to mark whether they were not comfortable, semicomfortable, or confident with diagnostic/exam or management skills regarding specific topics (such as orbital cellulitis, orbital fracture, retrobulbar hemorrhage, etc.). - Table 2 presents the responses from question 4 in aggregate and shows that, in total, after answering the survey questions, R1s marked a total of 149 responses, R2s 104 responses, and 
Table 1 Survey questions administered to ED (emergency department) residents

\begin{tabular}{|c|c|c|}
\hline & $\begin{array}{l}\text { Wherever you work after graduation, do you anticipate } \\
\text { having ophthalmology consultation services easily } \\
\text { available? }\end{array}$ & $\begin{array}{l}\text { A) Yes, similar to the current availability } \\
\text { B) Available, but less so } \\
\text { C) No } \\
\text { D) Not sure }\end{array}$ \\
\hline 2) & $\begin{array}{l}\text { I believe that knowing how to examine and manage patients } \\
\text { with eye complaints will be important to my future career }\end{array}$ & $\begin{array}{l}\text { Scale of } 1 \text { (not at all important) through } 10 \text { (very } \\
\text { important) }\end{array}$ \\
\hline 3) & I feel comfortable with the basic slit lamp exam & $\begin{array}{l}\text { Scale of } 1 \text { (not at all comfortable) through } 10 \text { (very } \\
\text { comfortable) }\end{array}$ \\
\hline $\begin{array}{l}\text { 4) } \\
\text { A) } \\
\text { B) } \\
\text { C) }\end{array}$ & $\begin{array}{l}\text { Diagnosis and exam skills: If a patient were to present with } \\
\text { the following condition or complaint, I would feel: } \\
\text { Confident about my diagnosis and exam skills, to the extent } \\
\text { that an ED provider is able to perform (i.e., an ED provider } \\
\text { would not be able to do a full dilated exam for a patient with } \\
\text { floaters, but would be able to do an ultrasound) } \\
\text { Semicomfortable with my diagnosis and exam skills, but } \\
\text { would appreciate more experience } \\
\text { Not comfortable with my diagnosis or examination abilities, } \\
\text { would definitely need review } \\
\text { Management skills: If a patient were to present with the } \\
\text { following condition or complaint, I would feel: } \\
\text { Confident about my management skills, to the extent that an } \\
\text { ED provider is able to perform: I know when patients with this } \\
\text { issue would need an ophthalmology consult and know the } \\
\text { appropriate history and physical to take, as well as medica- } \\
\text { tions, procedures and imaging necessary to order prior to a } \\
\text { consultation (if applicable) } \\
\text { Semicomfortable with my management: I may or may not } \\
\text { know when patient with this condition would need a consult } \\
\text { or I feel comfortable performing only some but not all of the } \\
\text { management steps } \\
\text { Not comfortable with my management: I would not know } \\
\text { when a patient with this condition would need a consult or I } \\
\text { do not know most of the management steps to take }\end{array}$ & $\begin{array}{l}\text { Orbital cellulitis } \\
\text { Orbital fracture } \\
\text { Retrobulbar hemorrhage } \\
\text { Corneal abrasion } \\
\text { Corneal ulcer } \\
\text { Chemical burn } \\
\text { Corneal foreign body } \\
\text { Iritis } \\
\text { Hyphema } \\
\text { Ocular herpetic conditions } \\
\text { Ruptured globe } \\
\text { Patient who presents with "floaters" } \\
\text { Patient who presents with high eye pressure } \\
\text { Patient who presents with "double vision" } \\
\text { Patient who presents with abnormal pupils }\end{array}$ \\
\hline & $\begin{array}{l}\text { If applicable, what do you feel has limited your comfort level } \\
\text { or experience with eye patients? Check all that apply. }\end{array}$ & $\begin{array}{l}\text { A) Not enough patients } \\
\text { B) There are enough patients, but I do not have enough } \\
\text { time to spend thinking about/examining them amongst } \\
\text { the other patients that I have to manage } \\
\text { C) There are enough patients, but I do not have enough } \\
\text { didactics/lectures to know how to manage them } \\
\text { D) There are enough patients, but I do not have enough } \\
\text { experience with physical exam skills to examine them } \\
\text { E) Not applicable, I feel very comfortable with most eye } \\
\text { problems }\end{array}$ \\
\hline
\end{tabular}

R3s 113 responses, making a total of 366 responses. - Table 3 presents the data from question 5 in aggregate, and shows that, in total, R1s marked a total of 180 responses, R2s 90 responses, and R3s 119 responses, making a total of 389 responses.

Out of these 366 responses for question 4, only in $18.9 \%$ (69/366) of responses did a resident mark that they were "confident" about their diagnostic or exam skills. In responses to question 5 , this decreased to $17.2 \%(67 / 289)$ for management skills in question 5 . There was an overall increase in confidence each year of residency. However, even among the R3s, only $42.5 \%$ (48/113) of responses indicated confidence in diagnostic or exam skills, and even fewer $36.1 \%$ (43/119) of responses indicated confidence in management skills. Chi-square testing revealed that the difference in proportions of R1s, R2s, and R3s marking whether they were not comfortable, semicomfortable, or confident was significant $(p<0.001)$ for both questions 4 and 5 .

-Figures 4 and 5 illustrate the responses to questions 4 and 5 in graphical format, and categorize by condition and residency levels the comfort level of residents in their diagnostic, exam, and management skills.

In - Fig. 6, residents revealed that there were a variety of reasons why their comfort level with eye patients was limited. Importantly, only one R3 marked that they were "very comfortable" with the eye exam.

\section{Discussion}

Given the increase in patients presenting to EDs with eye related complaints, ${ }^{1}$ it is essential that the comfort level of ED physicians with ophthalmologic patients increases. As prior 


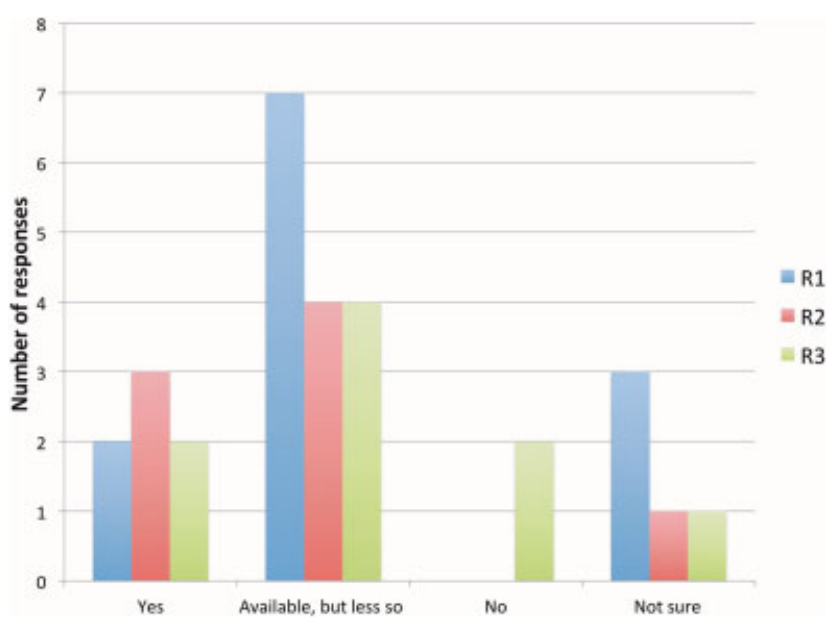

Fig. 1 Wherever you work after graduation, do you anticipate having ophthalmology consultation services easily available?

authors have noted, EDs, except at level 1 trauma centers, are not routinely staffed by ophthalmology consultants. ${ }^{1,3}$ Indeed, in our survey of ED residents, the majority indicated that they do not anticipate having similar availability of ophthalmology consultation services postgraduation (-Fig. 1).

ED providers desire increased ophthalmology knowledge and skills. In a survey of Denver Health Emergency Medicine graduates (a 4-year EM program), slit lamp usage was identified as an exam skill in which respondents felt significantly under-prepared. ${ }^{2}$ As a reference, respondents felt that they were significantly over-prepared in ultrasound usage and arterial line placement. In another survey among ED physicians in Australia, more than 92\% of the respondents desired further education in "ophthalmic emergencies."4 This ranked only second to neonatology emergencies and was desired above otolaryngology, pediatric, obstetrics and gynecology, toxicology, envenomation, behavioral disturbance, altered conscious state, and triage-related topics. ${ }^{4}$ Our study corroborates this desire for ophthalmic education, with participants overall believing ophthalmic exam and management skills to be important (-Fig. 2).

Unfortunately, despite this increased interest, there is insufficient training of ED physicians. In a survey administered in 1993 to ED physicians in the United Kingdom, 26.0\% of respondents received no training in eye emergencies, $68.8 \%$ had little to no confidence in these situations, and $42.2 \%$ worked in a department without slit lamps. ${ }^{8}$ A repeat survey conducted in 2003 showed that, although the proportion of ED physicians working in departments with usable slit lamps increased, $63.9 \%$ still felt little to no confidence in dealing with eye emergencies. ${ }^{9}$

The above trends are corroborated in our study. We demonstrate that EM residents, on average, do improve each year in terms of comfort level with the slit lamp exam, but unfortunately even as R3s many are not fully comfortable (-Fig. 3). The comfort level in diagnosing and managing various common eye complaints also increases with each residency year (-Figs. 4 and $\mathbf{5}$ and - Tables $\mathbf{2}$ and 3). However, overall, out of 3rd year residents, less than half indicated "confidence" in ophthalmologic diagnostic, exam, and management skills.

Interestingly, -Figs. 4 and $\mathbf{5}$ illustrate that different ophthalmology conditions elicit different comfort levels. For example, no R3s indicated "not comfortable" for diagnosing or managing orbital cellulitis, orbital fractures, retrobulbar hemorrhages, corneal abrasions, corneal foreign bodies, ocular herpetic conditions, ruptured globes, or a patient who presents with floaters, elevated intraocular pressure, double vision, or abnormal pupils. However, at least some R3s did indicate "not comfortable" for other conditions such as corneal ulcer, chemical burn, iritis, and hyphema.

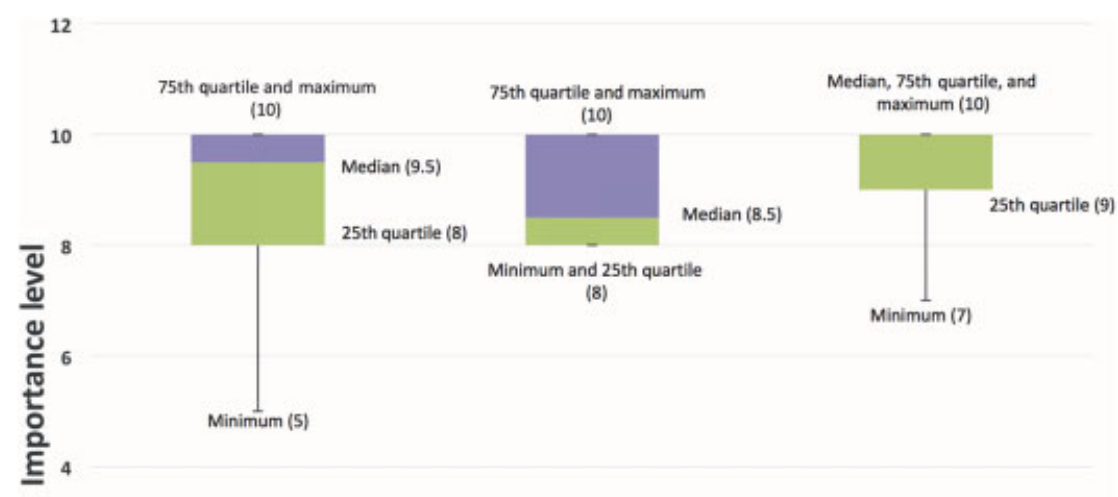

2

$\mathbf{0}$

R1

R2

R3

Fig. 2 I believe that knowing how to examine and manage patients with eye complaints will be important to my future career. ( 1 = not at all important through 10 = very important). 


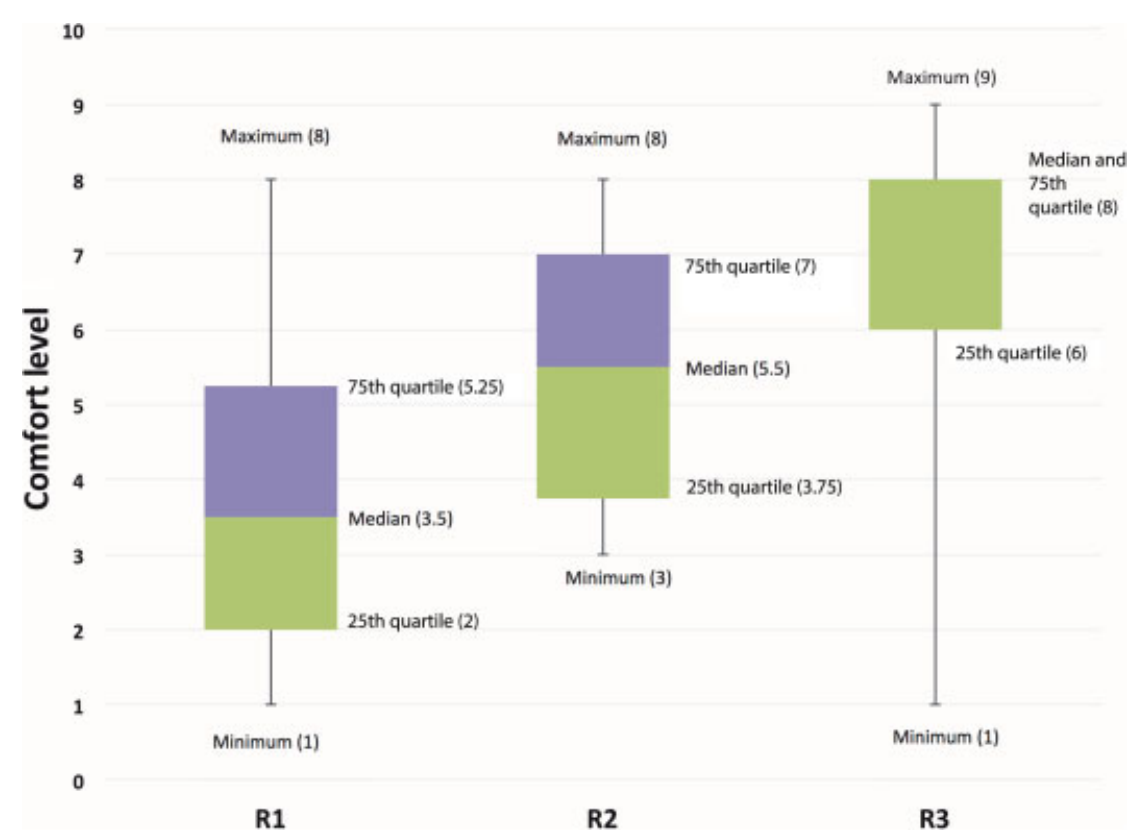

Fig. 3 I feel comfortable with the basic slit lamp exam ( $1=$ not at all comfortable through $10=$ very comfortable).

Table 2 Diagnosis and exam skill comfort level

\begin{tabular}{|l|l|l|l|l|}
\hline & R1 responses & R2 responses & R3 responses & R1-R3 responses \\
\hline Not comfortable (\%) & $33 / 149(22.1)$ & $32 / 104(30.8)$ & $5 / 113(4.4)$ & $70 / 366(19.1)$ \\
\hline Semicomfortable (\%) & $107 / 149(71.8)$ & $60 / 104(57.7)$ & $60 / 113(53.1)$ & $227 / 366(62.0)$ \\
\hline Confident (\%) & $9 / 149(6.0)$ & $12 / 104(11.5)$ & $48 / 113(42.5)$ & $69 / 366(18.9)$ \\
\hline Total & 149 & 104 & 113 & 366 \\
\hline
\end{tabular}

Abbreviations: R1, 1st year resident; R2, 2nd year resident; R3, 3rd year resident.

Note: Difference in proportions of R1s, R2s, and R3s marking whether they were not comfortable, semicomfortable, or confident is significant $(p<0.001)$.

Table 3 Management comfort level

\begin{tabular}{|l|l|l|l|l|}
\hline & R1 responses & R2 responses & R3 responses & R1-R3 responses \\
\hline Not comfortable (\%) & $48 / 180(26.7)$ & $16 / 90(17.8)$ & $2 / 119(1.7)$ & $66 / 389(17.0)$ \\
\hline Semicomfortable (\%) & $131 / 180(72.8)$ & $51 / 90(56.7)$ & $74 / 119(62.2)$ & $256 / 389(65.8)$ \\
\hline Confident (\%) & $1 / 180(0.6)$ & $23 / 90(25.6)$ & $43 / 119(36.1)$ & $67 / 389(17.2)$ \\
\hline Total & 180 & 90 & 119 & 389 \\
\hline
\end{tabular}

Abbreviations: R1, 1st year resident; R2, 2nd year resident; R3, 3rd year resident.

Note: Difference in proportions of R1s, R2s, and R3s marking whether they were not comfortable, semicomfortable, or confident is significant $(p<0.001)$.

Lack of comfort with eye emergencies continues to be an issue, both in the U.S. and abroad, and amongst U.S. EM residents in both 3-year and 4-year training programs. This highlights the need for a fresh approach. There were a variety of reasons indicated by residents in our study for their lack of comfort ( - Fig. 6). These included not enough patients, time, didactics, and/or hands-on examination experience related to eye emergencies.

This suggests that there could be a multimodal educational approach towards addressing this issue. For example, it has been shown that the amount of ophthalmic education in medical school has progressively decreased, ${ }^{10,11}$ and perhaps this could be a starting point for increased education amongst EM residents. Other studies have shown a lack of easy-to-navigate, illustrated, and useful texts for ED providers regarding common ophthalmologic emergencies, and this could also be a method to increase ophthalmology education during EM residency. ${ }^{12}$

Another potential solution is incorporating "residents-aseducators" in the ED. Ophthalmology and EM residents often interact during their training on call during real-time ED consultations. Ophthalmology resident educators have been well received in prior educational interventions, ${ }^{13}$ and this method of education has been enthusiastically endorsed by other authors. ${ }^{10}$ Specifically, it was previously demonstrated that ophthalmology residents who completed a teaching 
12

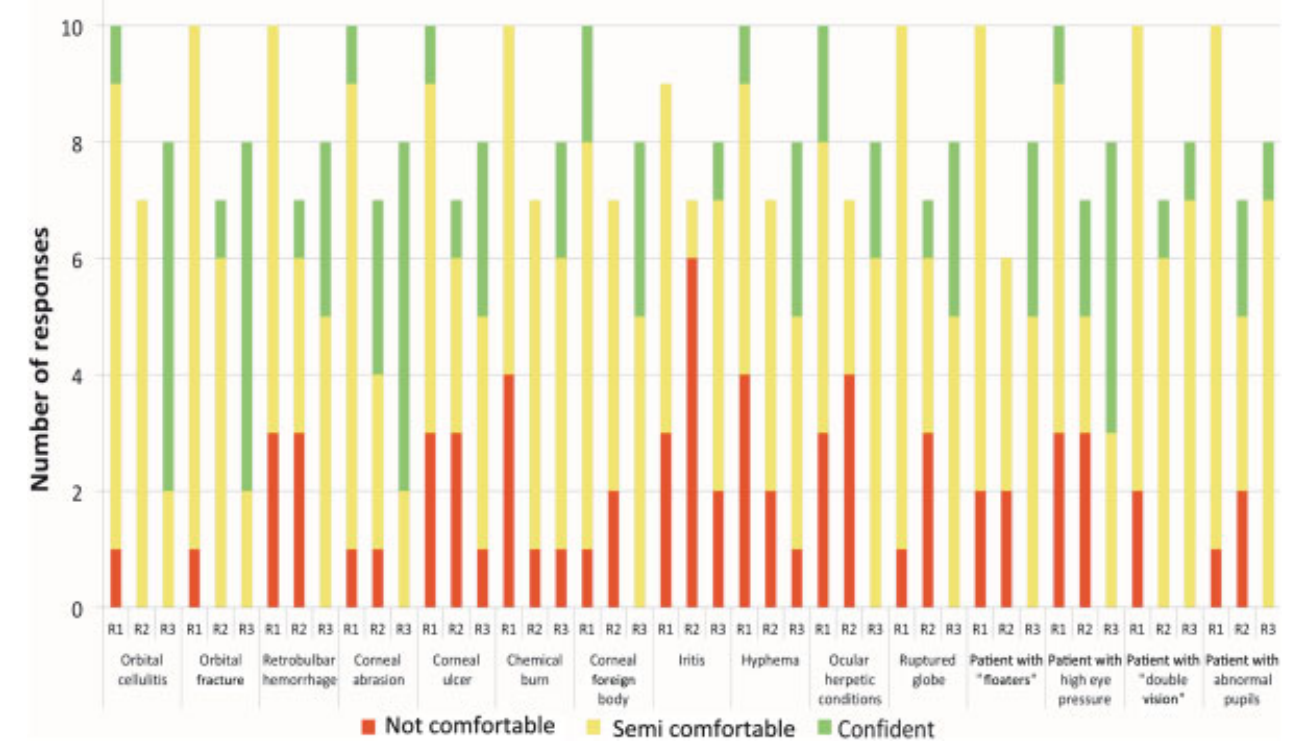

Fig. 4 If a patient were to present with the following condition or complaint, I would feel ( $\mathrm{A}=$ confident, $\mathrm{B}=$ semicomfortable, or $\mathrm{C}=$ not comfortable $)$. about my Diagnosis and Exam Skills.

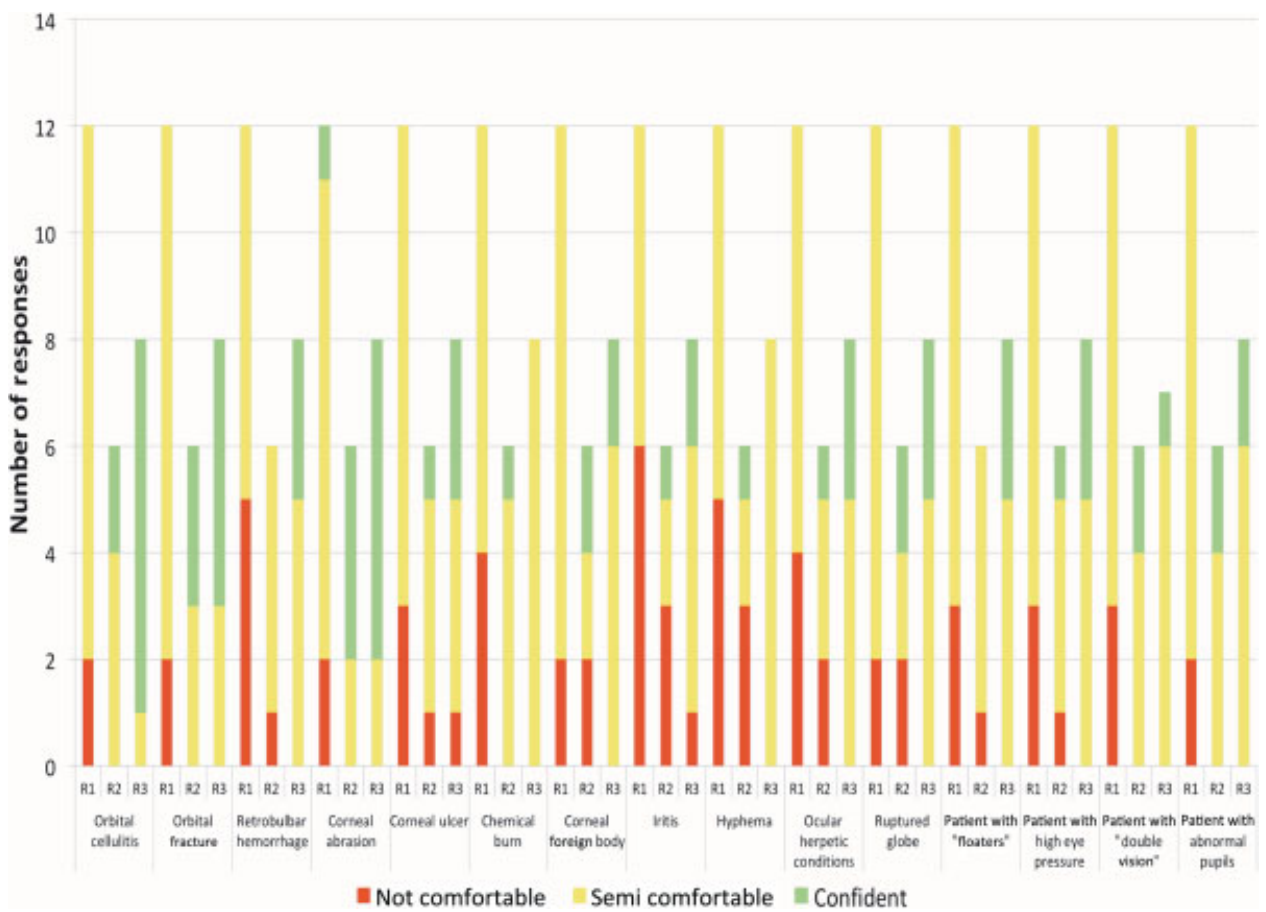

Fig. 5 If a patient were to present with the following condition or complaint, I would feel ( $\mathrm{A}=$ confident, $\mathrm{B}=$ semicomfortable, or $\mathrm{C}=$ not comfortable). about my Management Skills.

module were as effective as faculty members in leading medical student teaching sessions. ${ }^{13}$ In our study, qualitatively, EM residents were enthusiastic about "in-the-moment" teaching from ophthalmology residents. Examples of responses included "... have had (ophthalmology) residents teach me in the ED and it is very educational," and "... great when (ophthalmology) resident grabs ED resident in ED to show findings/exam on patient, even when busy." However, most acknowledged time constraints, for example, "only chal- lenge is time constraint, for both ED and ophthalmology residents." Perhaps targeted in the moment teaching, acknowledging time constraints, could be focused toward the specific high yield items identified in -Figs. $\mathbf{4}$ and $\mathbf{5}$ that residents felt the least comfortable diagnosing and managing.

There are limitations to this study. The specific conditions or symptoms posed in questions 4 and 5 were based upon review of past literature, but were by no means comprehensive, and expanding the survey to include other conditions could be 


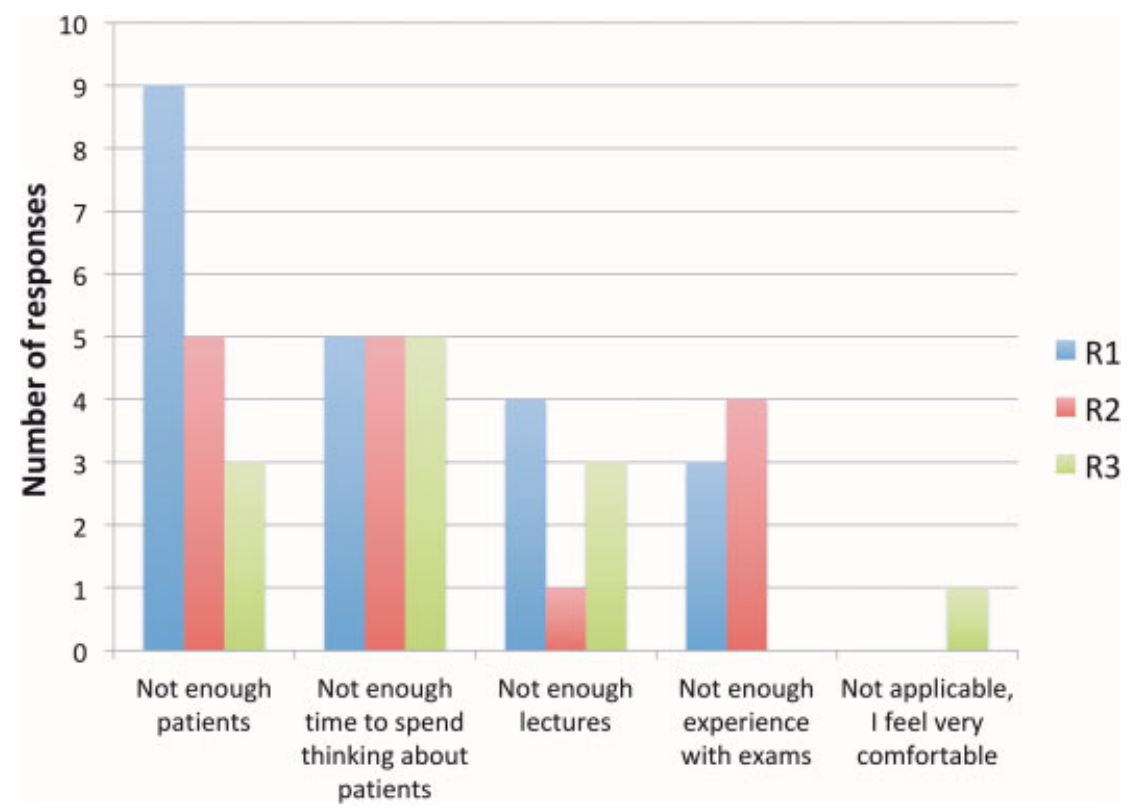

Fig. 6 If applicable, what do you feel has limited your comfort level or experience with eye patients? Check all that apply.

performed in the future. ${ }^{3,6,7}$ Another limitation is the small sample size, and the uni-institutional nature of the study. However, we do believe that results are generalizable given that they concur very well with prior research. It should also be noted that there is a difference between competence and confidence, and that our survey questions targeted confidence levels. However, without a validated method for gauging ophthalmic skills amongst ED providers, we rely on our survey results at the present time to serve as a proxy for competency in ophthalmic skills. This does, however, suggest an interesting avenue for future research evaluating the competency of ED providers on ophthalmic examination skills. We also note that these surveys were anonymous and thus participants were not influenced by concern regarding peer perceptions.

\section{Conclusions}

In conclusion, there is both need and desire for increased ophthalmic skills training for emergency department residents. Possible solutions will need to be innovative and multifactorial to target this goal.

\section{Conflict of Interest}

None declared.

\section{Acknowledgments}

Departmental support from Research to Prevent Blindness (D.F. and K.W.).

Stanford Clinical Teaching Seminar Series (D.F., K.W., and S.R.W.).

\section{References}

1 Stagg BC, Shah MM, Talwar N, Padovani-Claudio DA, Woodward MA, Stein JD. Factors affecting visits to the emergency depart- ment for urgent and nonurgent ocular conditions. Ophthalmology 2017;124(05):720-729

2 Druck J, Valley MA, Lowenstein SR. Procedural skills training during emergency medicine residency: are we teaching the right things? West J Emerg Med 2009;10(03):152-156

3 Magauran B. Conditions requiring emergency ophthalmologic consultation. Emerg Med Clin North Am 2008;26(01):233-238, viii viii.

4 Dent AW, Weiland TJ, Paltridge D. Australasian emergency physicians: a learning and educational needs analysis. Part four: CPD topics desired by emergency physicians. Emerg Med Australas 2008;20(03):260-266

5 Counselman FL, Borenstein MA, Chisholm CD, et al; EM Model Review Task Force; American Board of Emergency Medicine. The 2013 model of the clinical practice of emergency medicine. Acad Emerg Med 2014;21(05):574-598

6 Channa R, Zafar SN, Canner JK, Haring RS, Schneider EB, Friedman DS. Epidemiology of eye-related emergency department visits. JAMA Ophthalmol 2016;134(03):312-319

7 Vaziri K, Schwartz SG, Flynn HW Jr, Kishor KS, Moshfeghi AA. Eyerelated emergency department visits in the United States, 2010. Ophthalmology 2016;123(04):917-919

8 Tan MM, Driscoll PA, Marsden JE. Management of eye emergencies in the accident and emergency department by senior house officers: a national survey. J Accid Emerg Med 1997;14(03): 157-158

9 Sim D, Hussain A, Tebbal A, Daly S, Pringle E, Ionides A. National survey of the management of eye emergencies in the accident and emergency departments by senior house officers: 10 years onhas anything changed? Emerg Med J 2008;25(02):76-77

10 Quillen DA, Harper RA, Haik BG. Medical student education in ophthalmology: crisis and opportunity. Ophthalmology 2005; 112(11):1867-1868

11 Lippa LM, Boker J, Duke A, Amin A. A novel 3-year longitudinal pilot study of medical students' acquisition and retention of screening eye examination skills. Ophthalmology 2006;113(01):133-139

12 O'Connor PM, Crock CT, Dhillon RS, Keeffe JE. Resources for the management of ocular emergencies in Australia. Emerg Med Australas 2011;23(03):331-336

13 Ryg PA, Hafler JP, Forster SH. The Efficacy of Residents as Teachers in an Ophthalmology Module. J Surg Educ 2016;73(02):323-328 